\title{
The early recognition of ureteral injury after gynecological surgery and the technique of endoscopic placement of ureteral stents
}

\author{
kai Deng ${ }^{1}$, yuan $\mathrm{Chen}^{1}$, ning $\mathrm{Xie}^{1}$, gui Wang ${ }^{1}$, xin $\mathrm{Zhang}^{1}$, qian $\mathrm{Yang}^{1}$, qin $\mathrm{Hu}^{1}$, qi Huang${ }^{1}$, \\ and qi Ruan ${ }^{1}$ \\ ${ }^{1}$ Shunde Hospital of Southern Medical University
}

May 15, 2020

\begin{abstract}
Objective: To investigate the early recognition of ureteral injury in gynecological operation and improve the technique of endoscopic placement of ureteral stents. Design:Retrospectively analyze the clinical and prognostic data of iatrogenic ureteral injuries in gynecological operations in our institution from 2013 to 2019. Setting: Shunde Hospital, Southern Medical University. Population: Women with iatrogenic ureteral injury due to gynecological surgery. Methods: To analyze the causes, clinical manifestations, early identification methods and surgical techniques for repairing ureteral injuries of patients with iatrogenic ureteral injuries. Main outcome measures:Time to discover ureteral injury by different methods and success rate of ureteral injury repair. Results: 13 cases were delayed diagnosis, of which 4 cases were confirmed by pelvic drainage urinary creatinine detection at $6.50 \pm 3.11$ days after operation, and 9 cases were diagnosed by pyelography after $36.8 \pm 12.36$ days after operation. Ureteroscopy + retrograde ureteral stent placement were the first choices. Seven patients (53.85\%) were successful. Three patients who failed repair operation immediately used cis-percutaneous nephroscopy combined with retrograde ureteroscopy to successfully place ureteral stents. Among the 10 patients who successfully placed stents, 9 patients were cured except for 1 case of renal insufficiency. Conclusions: The liquid creatinine test for recognition of ureteral injury after gynecological surgery is effective.For some serious ureteral injuries, percutaneous renal anterograde combined with retrograde ureteroscopy and ureteral stent placement can improve the success rate of intubation.
\end{abstract}

\section{Hosted file}

Ureteral injury and ureteral stent implantation.doc available at https://authorea.com/users/ 322243/articles/451310-the-early-recognition-of-ureteral-injury-after-gynecologicalsurgery-and-the-technique-of-endoscopic-placement-of-ureteral-stents

\section{Hosted file}

Ureter Injury Intubation Form.doc available at https://authorea.com/users/322243/articles/ 451310-the-early-recognition-of-ureteral-injury-after-gynecological-surgery-and-thetechnique-of-endoscopic-placement-of-ureteral-stents 